\title{
Central serous papillopathy by optic nerve head drusen
}

This article was published in the following Dove Press journal:

Clinical Ophthalmology

24 November 2010

Number of times this article has been viewed

\author{
Ana Marina Suelves' \\ Ester Francés-Muñoz' \\ Roberto Gallego-Pinazo' \\ Diamar Pardo-Lopez' \\ Jose Luis Mullor ${ }^{2}$ \\ Jose Fernando Arevalo 3 \\ Manuel Díaz-Llopis ${ }^{1,4,5}$ \\ 'Department of Ophthalmology, La Fe \\ University Hospital, Valencia, Spain; \\ ${ }^{2}$ Instituto de Investigación Sanitaria, \\ Fundación para la investigación, \\ La Fe Hospital, Valencia, Spain; \\ ${ }^{3}$ Retina and vitreous service, Clínica \\ Oftalmológica Centro Caracas, \\ Caracas DC, Venezuela; ${ }^{4}$ Department \\ of Ophthalmology, University of \\ Medicine, Valencia, Spain; ${ }^{5} \mathrm{CIBERER}$, \\ The Biomedical Network Research \\ Centre on Rare Diseases, Valencia, \\ Spain
}

Correspondence: Ana Marina Suelves C/Jose Vicente Casabán Sena, 2 Escalera 3, Pta 19, Xirivella (46950), Valencia, Spain Tel +34630070737

Email ana.suelves@gmail.com
Abstract: We report a 38-year-old man with a complaint of blurred vision in his right eye for the previous 5 days. He had bilateral optic disc drusen. Fluorescein angiography revealed multiple hyperfluorescent foci within temporal optic discs and temporal inferior arcade in late phase. Optical coherence tomography showed bilateral peripapillary serous detachment as well as right macular detachment. This is the first reported case of a concurrent peripapillary and macular detachment in a patient with central serous papillopathy by optic disc drusen. Central serous papillopathy is an atypical form of central serous chorioretinopathy that should be considered as a potential cause of acute loss of vision in patients with optic nerve head drusen.

Keywords: central serous papillopathy, peripapillary central serous chorioretinopathy, optic nerve head drusen, peripapillary subretinal fluid

\section{Introduction}

Optic nerve head drusen (ONHD) are hyaline material calcificated deposits due to an axoplasmic transport alteration in the presence of a small scleral canal. ${ }^{1,2}$ They are a casual fundus finding but are rarely complicated with a peripapillary choroidal neovascularization, an anterior ischemic optic neuropathy, or a central serous papillopathy (CSP). ${ }^{3}$ Herein, we report a patient with bilateral peripapillary and right macular serous detachment as first manifestation of ONHD.

\section{Case report}

A 38-year-old man presented with complaint of progressive loss of vision for five days in his right eye. Past systemic and ocular history was unremarkable, but flu was reported three weeks before. The diagnosis given by another physician was bilateral viral papillitis. He denied pain on eye movements, discromatopsy, and took no prescription medications. Visual acuity was 20/30 in the right eye and 20/20 in the left eye. Pupils were of equal size and constricted briskly without a relative afferent pupil defect when exposed to direct light. Extraocular movements and biomicroscopic examination of the anterior ocular segment were normal. Fundus examination revealed bilateral ONHD (Figures 1 and 2). The right eye showed a serous detachment extending from optic nerve to macula (Figures 1 and 3). Fluorescein angiography showed autofluorescence of the disk drusen (Figure 4) and abnormal hyperfluorescence from temporal optic discs in early phases (Figure 5). Our patient also presented one hyperfluorescent focus in lower part of right optic nerve head (Figure 5) and multiple pinpoint foci of hyperfluorescence within temporal inferior veins in late frames (Figure 5). A cranial 


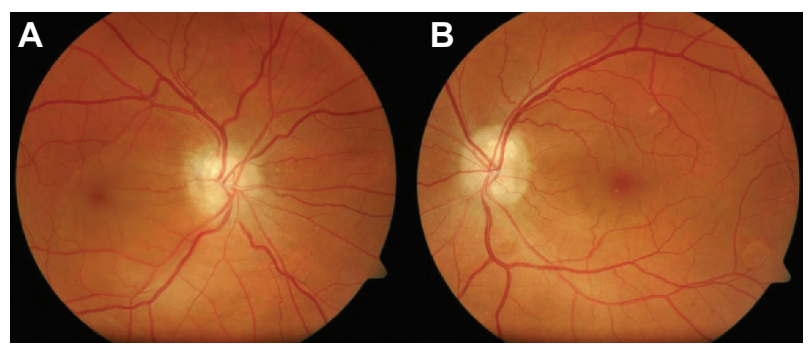

Figure I A, B) Fundus photograph shows with a bilateral peripapillary and a macular detachment extending from the right optic disc to the macula. B) In left eye, two anular images correspond to pigment epithelium detachments within inferior temporal vein

tomography scan showed calcium density bodies at both head optic nerves (Figure 6). Automated static perimetry demonstrated a bilateral enlargement of the blind spot. After two months most of subretinal fluid disappeared (Figure 7) with no treatment and visual acuity improved to 20/20 in both eyes. No relapses occurred during one-year follow-up.

\section{Discussion}

ONHD are an uncommon congenital entity. Evidence suggests that axoplasmic transport alteration and axonal degeneration are involved in disc drusen formation. Most patients are asymptomatic ${ }^{4}$ and visual acuity is normally well preserved. ${ }^{5}$ When a rapid decrease of visual acuity appear in these patients, the differential diagnosis should include anterior ischemic optic neuropathy, central retinal artery or vein occlusion, peripapillary choroidal neovascularization, ${ }^{6,7}$ and CSP. ${ }^{8,9}$

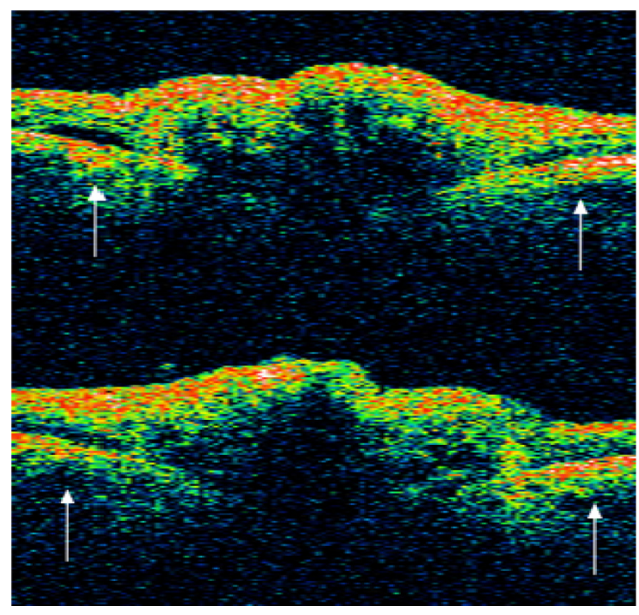

Figure 2 Stratus OCT 3 (Stratus Optical Coherence Tomography 3; Carl Zeiss Meditec, Dublin, CA, USA). The Stratus OCT shows an elevated optic nerve head with a signal-poor region below the surface and a peripapillary serous detachment (white arrows) in both eyes.
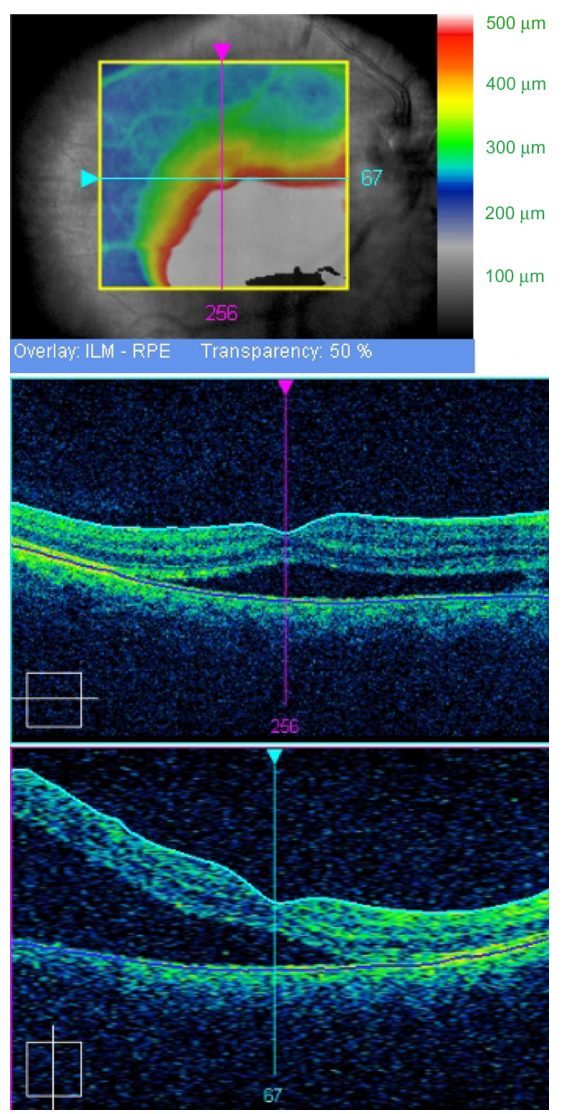

Figure 3 Optical Coherence Tomography Cirrus (Carl Zeiss Meditec, Dublin, CA, USA), macular thickness. It shows a huge neurosensory detachment from disc to macula in right eye.

Central serous chorioretinopathy (CSC) is a condition characterized by accumulation of transparent fluid under the neurosensory retina, retinal pigment epithelium (RPE), or both, causing a circumscribed macular detachment or RPE detachments. The pathophysiology of CSC remains poorly understood, but focal choroidal hyperpermeability has been

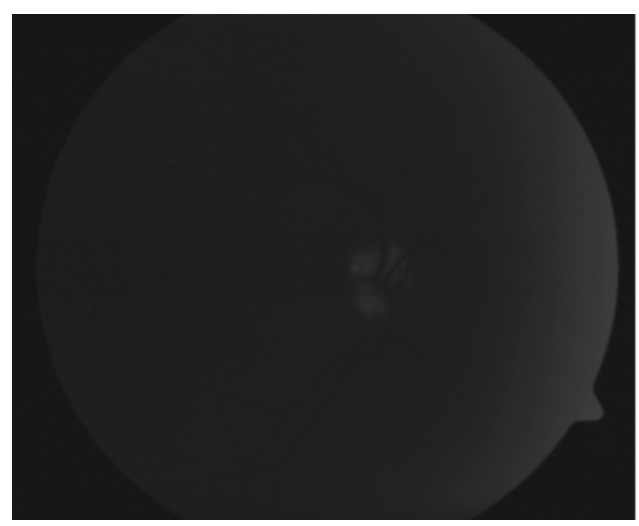

Figure 4 The preinjection photograph shows the characteristic autofluorescence of drusen. 


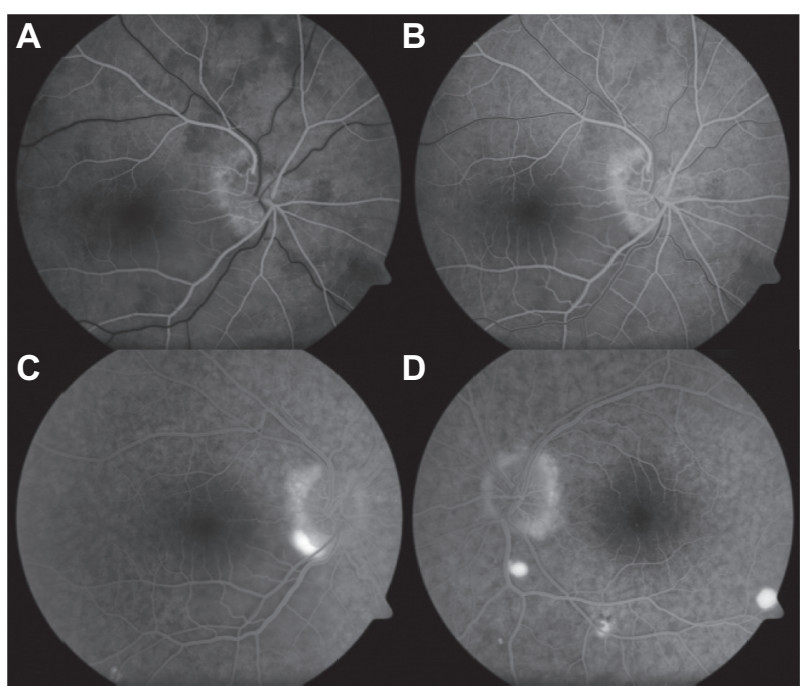

Figure 5 (A, B) Early phase fluorescein angiogram demonstrates hyperfluorescence within temporal disc optic, with appearance in mid-phase and late phase of multiple pinpoint foci of hyperfluorescence (C, D).

recently implicated..$^{10}$ An exceptional form of CSC is CSP that may occur in normal optic disc or in those with a pit or coloboma.

In our patient, spontaneous reabsorption of fluid and "benign" evolution ruled out a peripapillary choroidal neovascularization, suggesting CSP as a final diagnosis. Moisseiev et al described a case of optic disc drusen and CSP. ${ }^{11}$ We report the second case in literature describing simultaneous occurrence of optic nerve drusen and CSP, but the first one in which both bilateral peripapillary and macular detachment are observed. Optic nerve drusen seems to alter

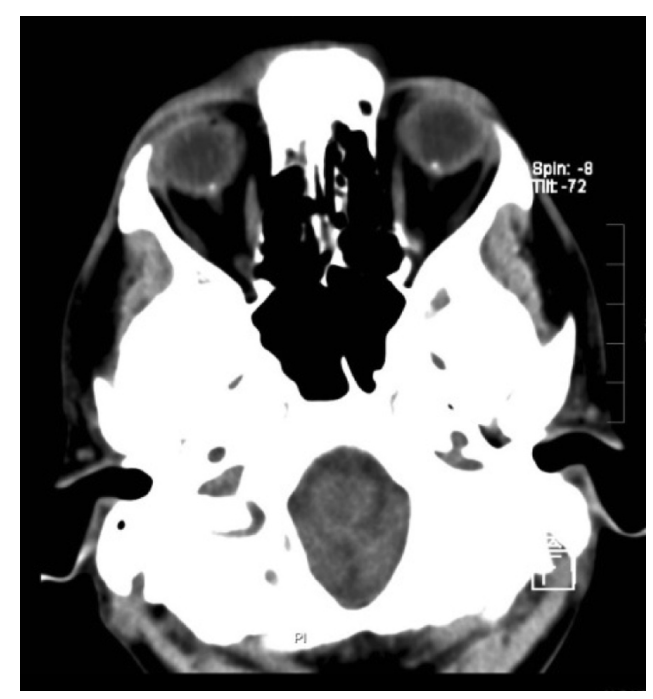

Figure 6 Axial computed tomography demonstrating high attenuation in both optic discs, consistent with drusen calcificated.
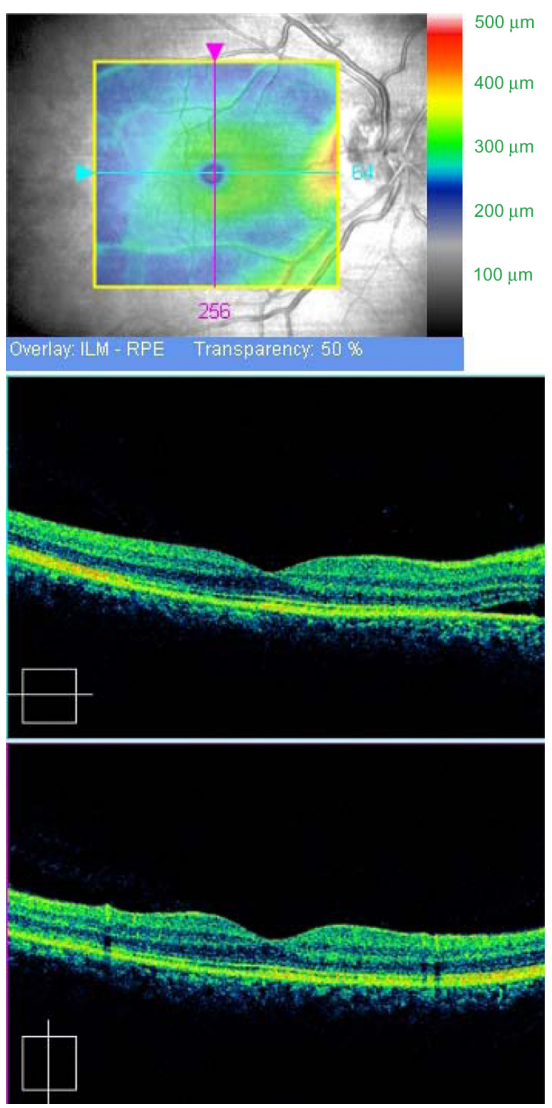

Figure 7 Optical Coherence Tomography Cirrus (Carl Zeiss Meditec, Dublin, CA, USA). The right macular detachment has disappeared.

the normal barrier between the prelaminar optic nerve and the peripapillary retina. This anomalous peripapillary area joined to focal hyperpermeability seen in CSC may act together in the subretinal fluid production in patients with ONHD. It is critical to correctly diagnose patients with CSP to avoid unnecessary work-up and overlooking potential serious conditions such as true papilledema. CSP should be considered as a potential cause for acute loss of vision in patients with optic nerve head drusen.

\section{Disclosure}

The authors of this article have no proprietary or commercial interest in any materials or method discussed in this article.

\section{References}

1. Auw-Haedrich C, Staubach F, Witschel H. Optic disk drusen. Surv Ophthalmol. 2002;47:515-532.

2. Tso MOM. Pathology and pathogenesis of drusen of the optic nerve head. Ophthalmol. 1981;88:1066-1080.

3. Lee AG, Zimmerman MB. The rate of visual field loss in optic nerve head drusen. Am J Ophthalmol. 2005;139:1062-1066.

4. Wilkins JM, Pomeranz HD. Visual manifestations of visible and buried optic disc drusen. J Neuroophthalmol. 2004;24:125-129. 
5. Lee AG, Zimmerman MB. The rate of visual field loss in optic nerve head drusen. Am J Ophthalmol. 2005;139:1062-1066.

6. Brown SM, del Monte MA. Choroidal neovascular membrane associated with optic head nerve drusen in a child. Am J Ophthalmol. 1996; 121:215-217.

7. Kies JC, Bird AC. Juxtapapillary choroidal neovascularization in older patients. Am J Ophthalmol. 1988;105:9-11.

8. Brodsky MC. Central serous papillopathy. Br J Opthalmol. 1999;83: 878-884.
9. Johnson D. Atypical central serous chorioretinopathy with peripapillary subretinal fluid suggesting an optic neuropathy. J Neuro-Ophtalmol. 2009;29:155-156

10. Pryds A, Sander B, Larsen M. Characterization of subretinal fluid leakage in central serous chorioretinopathy. Invest Ophthalmol Vis Sci. 2010:26.

11. Moisseiev J, Cahane M, Treister G. Optic nerve head drusen and peripapillary central serous chorioretinopathy. Am J Ophthalmol. 1989;15:202-203.
Clinical Ophthalmology

\section{Publish your work in this journal}

Clinical Ophthalmology is an international, peer-reviewed journal covering all subspecialties within ophthalmology. Key topics include: Optometry; Visual science; Pharmacology and drug therapy in eye diseases; Basic Sciences; Primary and Secondary eye care; Patient Safety and Quality of Care Improvements. This journal is indexed on

\section{Dovepress}

PubMed Central and CAS, and is the official journal of The Society of Clinical Ophthalmology (SCO). The manuscript management system is completely online and includes a very quick and fair peer-review system, which is all easy to use. Visit http://www.dovepress.com/ testimonials.php to read real quotes from published authors. 